\title{
Effects of high and low preovulatory concentrations of progesterone on ovulation from the isolated perfused rabbit ovary
}

\author{
P. V. Holmes*, J. Sogn, E. Schillinger† and P. O. Janson \\ Departments of *Physiology and Obstetrics and Gynecology, University of Göteborg, Sweden, and \\ $\dagger$ Schering AG, Department of Biochemical Pharmacology, Berlin, Federal Republic of Germany
}

\begin{abstract}
Summary. Rabbit ovaries were isolated surgically before the ovulatory gonadotrophin stimulation and perfused in vitro. Untreated, control ovaries never ovulated. Ovaries treated in vitro with ovine $\mathrm{LH}$ ovulated $10-14 \mathrm{~h}$ later and the oocytes had undergone germinal vesicle breakdown (GVB). $\mathrm{LH}$ induced increases in progesterone secretion from the treated ovaries. A 3 $\beta$-hydroxysteroid dehydrogenase blocker ('Compound A') effectively reduced progesterone secretion into the perfusate and follicular fluid to very low levels but had no effect on ovulation rate or on oocyte maturation. Excessively high progesterone levels were obtained artificially in perfusates by addition of exogenous steroid; the number of ovaries ovulating was markedly reduced but there was no effect on oocyte maturation.

It is concluded that the rise in progesterone that normally occurs immediately after the LH surge is not a prerequisite for ovulation in the rabbit. However, progesterone may have a modifying effect on LH-induced follicle rupture when at a pharmacologically high level.
\end{abstract}

\section{Introduction}

Numerous studies on mammals have consistently shown that the surge of pituitary luteinizing hormone $(\mathrm{LH})$ elicits a rapid increase in steroid concentrations in ovarian venous blood and follicular fluid. For instance, in rabbits there is a rapid increase in progesterone, androgen and oestradiol, and about $2 \mathrm{~h}$ after the $\mathrm{LH}$ surge these values start to decline and are low or undetectable at the time of ovulation (LeMaire, Clark \& Marsh, 1979; Janson et al., 1982). On the basis of experiments in rats, in which ovulation was blocked by various blockers of steroidogenesis (Lipner \& Wendelken, 1971; Snyder, Beecham \& Schane, 1984), it may be suggested that the elevated steroid concentrations early in the ovulatory process might be important for the rupture of the follicle. In addition, conflicting reports of whether ovarian steroids may activate (Rondell, 1964) or inhibit (Hunzicker-Dunn, 1979) ovarian collagenolytic enzymes led LeMaire et al. (1982) to investigate the effect on ovulation of the known preovulatory decline in follicular oestradiol. LeMaire et al. (1982) found that it was not a prerequisite for ovulation in the rabbit under perfusion conditions. Since a similar decline in progesterone (YoungLai, 1972; Patwardhan \& Lanthier, 1979) has also been observed in rabbit follicular fluid before ovulation in vivo, further studies need to be carried out to determine whether the decline in this steroid is important for the ovulatory process.

\section{Materials and Methods}

Animals. The 25 virgin rabbits (Swedish Land albinos) were maintained before use in airconditioned quarters with natural lighting. Standard rabbit food pellets and fresh water were provided ad libitum. 
Surgical procedure and ovarian perfusion. The anaesthesia, the surgical procedure for extirpation and separate cannulation of the ovaries, and the perfusion system used have all been described in detail earlier (Janson et al., 1982; Holmes et al., 1983; Cajander et al., 1984). Briefly, both ovaries were removed from the animal and the arterial supply was cannulated either via an aortic segment containing the ovarian artery or directly via the ovarian artery. The ovaries were placed in separate organ chambers of the perfusion apparatus and were suspended by the ovarian ligament in their own venous effluent medium. The perfusions were carried out at $37-38^{\circ} \mathrm{C}$ in a recirculating system containing $70 \mathrm{ml}$ oxygenated medium for periods up to $21 \mathrm{~h}$. At pressures of $30-40 \mathrm{mmHg}$ (aortic cannulations) or $80-90 \mathrm{mmHg}$ (ovarian artery cannulations), the pulsatile pump gave flow rates of $2 \cdot 7-4.0$ and $1.0-1.5 \mathrm{ml} / \mathrm{min}$, respectively. At intervals of 1 or $2 \mathrm{~h}$ during the perfusion, $1 \mathrm{ml} \mathrm{medium}$ samples were withdrawn from the venous outflow and were frozen at $-70^{\circ} \mathrm{C}$ for steroid analyses. Each sample was immediately replaced by an equal volume of fresh medium.

A surgical microscope (Zeiss, magnification $2 \cdot 5$ to 40 ) allowed continuous observation of the ovaries and their developing follicles. In specific experiments, when follicular rupture was judged by stigma development to be imminent, after about $7 \mathrm{~h}$, the perfusions were stopped; bulging follicles with a diameter of more than $1 \mathrm{~mm}$ were punctured with a fixed-needle syringe (Hamilton $10 \mu \mathrm{l}$ ) and the follicular fluid and oocyte-cumulus complex were withdrawn. The fluid from all follicles of each ovary was pooled and was diluted up to $500 \mu \mathrm{l}$ with medium and was analysed later for steroids. Gentle spread preparations were made with the oocyte-cumulus complexes for analysis of germinal vesicle breakdown (GVB). Complexes were also collected from freshly ovulated follicles in other experiments with the use of specially pulled glass pipettes, the oocytes being analysed for GVB.

Chemicals, drugs and hormones. The perfusion medium consisted of Medium 199 with Earle's salts and L-glutamine (Gibco, Paisley, U.K.). $\mathrm{NaHCO}_{3}$ was added as buffer (0.026 $\left.\mathrm{M}\right)$ just before use, as was also benzyl penicillin G potassium $(75 \mu \mathrm{g} / \mathrm{ml}$, USP), streptomycin $(50 \mu \mathrm{g} / \mathrm{ml})$, heparin sulphate $(0.2$ units $/ \mathrm{ml})$, insulin $(0.02$ units $/ \mathrm{ml})$ and $4 \%$ essential fatty-acid free bovine serum albumin (Sigma Chemical Co., St Louis, MO, U.S.A). Bovine LH (NIH-LH-B9; 0.70 units/mg, FSH contamination $<0.05$ units $/ \mathrm{mg}$ ) was kindly supplied by NIAMDD, Bethesda, MD, U.S.A., and was dissolved in $0.15 \mathrm{M}-\mathrm{NaCl}$ for addition to the perfusion medium. The inhibitor of $3 \beta$-hydroxysteroid dehydrogenase, $17 \alpha$-(3'-hydroxypropyl)-1,3,5,6,8(9)-oestrapentaene-3,17 $\beta$-diol (German published patent application DE OS 3242894) ('Compound A') was provided by Schering AG, Berlin, Federal Republic of Germany. This steroid was dissolved in absolute alcohol for addition to the perfusion medium in the three final concentrations of $1.6 \times 10^{-5}, 3.2 \times 10^{-5}$ and $1.0 \times 10^{-4} \mathrm{M}$. These three concentrations were used in an attempt to inhibit totally the biosynthesis of progesterone. However, since total inhibition was not achieved with the concentrations used, and since no difference in effects by any of the doses was seen, it was decided to pool the results. The exogenous progesterone, also dissolved in absolute alcohol, and all other chemicals and reagents were of analytical grade and were obtained from Calbiochem-Behring (Marburg, FRG), Merck Co. (Darmstadt, FRG) or Sigma Chemicals Co. (St Louis, MO, U.S.A). [ $\left.{ }^{3} \mathrm{H}\right]$ oestradiol-17 $\beta$ and $\left[{ }^{3} \mathrm{H}\right]$ progesterone were purchased from the New England Nuclear Co., Boston, MA, U.S.A.

Steroid assays. Oestradiol-17 $\beta$ and progesterone concentrations in the perfusion medium were determined by radioimmunoassays as described previously (Hillensjö, Bauminger \& Ahrén, 1976). Antibody preparations used for these assays were kindly provided by the late Professor H. R. Lindner and by Dr F. Cohen of the Weizmann Institute, Rehovot, Israel. The sensitivity, betweenand within-assay coefficients of variation were $\sim 15 \mathrm{pg} / \mathrm{ml}, 15 \%$ and $6 \%$ for oestradiol and $\sim 15 \mathrm{pg} / \mathrm{ml}, 13 \%$ and $2 \%$ for progesterone.

Experimental protocol. The animals were treated only with pentobarbitone sodium (Mebumal, ACO Läkemedel, Stockholm, Sweden; $30 \mathrm{mg} / \mathrm{kg}$ i.v.) as the anaesthetic for surgery and both ovaries were excluded if corpora lutea were present. Otherwise they were placed in their respective 
perfusion chambers, one ovary acting as the control. After stabilization of perfusion for $1 \mathrm{~h}$, the ovaries received an LH stimulus of $0.75 \mu \mathrm{g} / \mathrm{ml}$ medium.

The high-progesterone experimental ovaries received $10 \mu \mathrm{g}$ progesterone $/ \mathrm{ml}$ medium with the LH stimulus while their controls received a corresponding amount of the alcohol vehicle. The Compound A-treated ovaries received the inhibitor when first placed in perfusion, their controls receiving equivalent alcohol vehicle. After perfusion for $1 \mathrm{~h}$ and just before the $\mathrm{LH}$ stimulus, the entire medium bathing the experimental and control ovaries was replaced by fresh medium containing the blocker and the vehicle, respectively. This procedure was adopted to dispose of progesterone flushed from the ovaries during the initial part of the perfusion, thus avoiding any influence from recirculating endogenous hormone.

\section{Results}

\section{Perfusion with Compound A}

Ovulations. Table 1 shows that there was no difference in the number of ovaries with ovulating follicles, the time of the first ovulation and the mean number of ovulations per ovulating ovary in those treated with LH plus Compound A present in the medium.

Steroid concentrations in medium and follicular fluid. After treatment with LH plus the inhibitor, the progesterone concentrations in the medium at the time of the first ovulation were only about $6 \%$ of the values seen after stimulation with $\mathrm{LH}$ without the inhibitor (Table 1). The concentrations of oestradiol-17ß, however, were not significantly different between the two treatments. Text-figure 1 illustrates the mean oestradiol and progesterone values in the medium throughout the perfusion period in the two groups before and at the time of ovulation. The concentrations of progesterone were significantly elevated from $1 \mathrm{~h}$ after addition of $\mathrm{LH}$.

The same tendency was observed when analysing the media of the two groups in which follicular fluid steroid content was examined before ovulation ( $7 \mathrm{~h}$ after LH; Text-fig. 2). Follicular fluid steroid content was investigated in 5 pairs of perfused ovaries $7 \mathrm{~h}$ after treatment with $\mathrm{LH}$ $(0.75 \mu \mathrm{g} / \mathrm{ml})$ with and without Compound $\mathrm{A}\left(1.6 \times 10^{-5}\right.$ to $\left.1.0 \times 10^{-4} \mathrm{M}\right)$. The mean \pm s.e.m. progesterone and oestradiol contents were $1154 \pm 741$ and $263 \pm 64 \mathrm{pg} /$ follicle, respectively, in the 30 follicles obtained from ovaries treated with LH only and $28 \pm 16$ and $161 \pm 97 \mathrm{pg} / \mathrm{follicle}$, respectively, in the 27 follicles from ovaries treated with LH plus Compound A. The follicular content of progesterone was significantly reduced by the presence of Compound A $(P<0.05$, paired $t$ test), while there was no significant difference in the oestradiol content.

Table 1. Ovulatory responses of and medium steroid concentrations from rabbit ovaries perfused in vitro after LH $(0.75 \mu \mathrm{g} / \mathrm{ml})$ with or without Compound $A\left(1.6 \times 10^{-5}-1 \times 10^{-4} \mathrm{M}\right)$

\begin{tabular}{lccc}
\hline & LH & LH + Compound A & $\begin{array}{c}\text { Significance } \\
\text { (paired } t \text { test) }\end{array}$ \\
\hline Total no. of ovaries & 7 & 7 & - \\
No. of ovaries with ovulating follicles & 5 & 6 & - \\
Total no. of ovulations & 14 & 23 & - \\
No. of ovulations/ovulating ovary & $2 \cdot 8 \pm 0.6$ & $3.8 \pm 0.7$ & N.S. \\
Time of first ovulation (h) & $7 \cdot 2 \pm 1 \cdot 3$ & $7 \cdot 5 \pm 1 \cdot 5$ & N.S. \\
Oestradiol level $(\mathrm{ng} / \mathrm{ml}$ ) just before LH & $0.5 \pm 0.3$ & $0.5 \pm 0.3$ & N.S. \\
Oestradiol $(\mathrm{ng} / \mathrm{ml}$ ) at first ovulation & $1 \cdot 6 \pm 0.4$ & $0.9 \pm 0.2$ & N.S. \\
Progesterone $(\mathrm{ng} / \mathrm{ml})$ just before LH & $13 \pm 6$ & $5 \pm 2$ & N.S. \\
Progesterone $(\mathrm{ng} / \mathrm{ml})$ at first ovulation & $436 \pm 94$ & $27 \pm 9$ & $P \leqslant 0.001$ \\
\hline
\end{tabular}

Values are mean \pm s.e.m. 

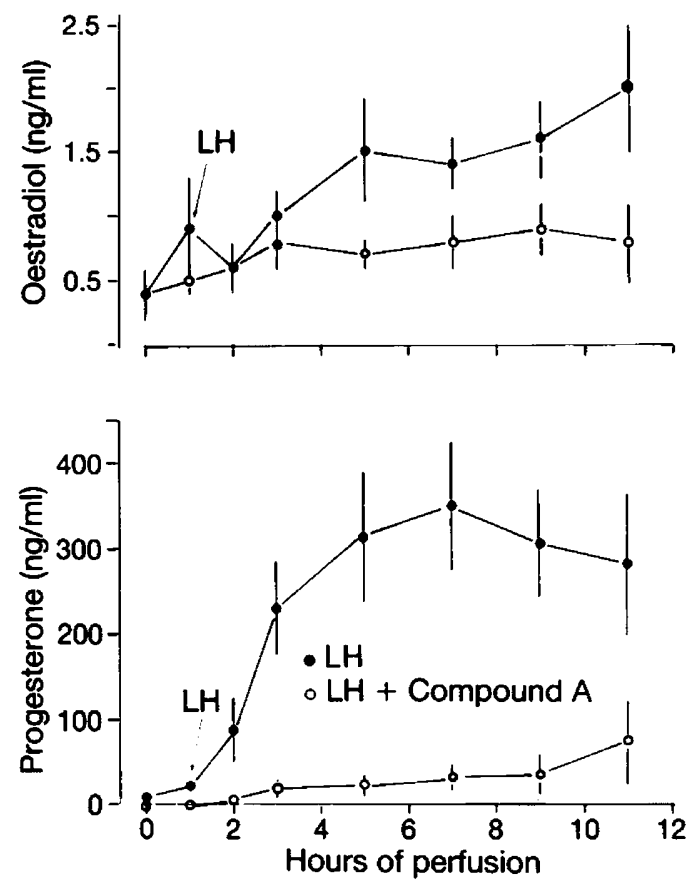

Text-fig. 1. Progesterone and oestradiol-17 $\beta$ concentrations (mean \pm s.e.m.) in the medium from 7 pairs of rabbit ovaries during the preovulatory period and at ovulation when perfused with Compound A $\left(1.6 \times 10^{-5}-1 \times 10^{-4} \mathrm{M}\right)$ or without the inhibitor. $\mathrm{LH}(0.75 \mu \mathrm{g} / \mathrm{ml})$ was added to both ovaries at $1 \mathrm{~h}$ of perfusion.

Oocyte maturation. In 3 experiments the maturational grade of the ovulated oocytes was investigated by assessing germinal vesicle breakdown (GVB). After treatment with $\mathrm{LH}, 4$ out of 4 oocytes collected precisely at the time of ovulation, had already undergone GVB and in all 6 oocytes ovulated after treatment with LH and Compound A, GVB had also already occurred.

\section{Ovulations and steroid concentrations in medium after perfusion with a high dose of progesterone}

There was a significant reduction in the number of ovaries with ovulating follicles after treatment with $\mathrm{LH}$ plus progesterone $(10 \mu \mathrm{g} / \mathrm{ml})$ compared with $\mathrm{LH}$ alone (Table 2$)$.

However, there was no significant difference in the time of first ovulation for those ovaries that ovulated. Moreover, there was no significant difference in the number of ovulations per ovulating ovary in the two groups, although a tendency existed for an increased ovulation frequency with high progesterone. To assess whether the addition of $10 \mu \mathrm{g}$ progesterone $/ \mathrm{ml}$ raised the concentrations of steroid in the medium, progesterone values in the medium were assayed at the end of perfusion in two experiments and were 8.6 and $7.6 \mu \mathrm{g} / \mathrm{ml}$.

\section{Discussion}

Using an in-vitro perfusion model for the rat ovary, Koos, Feiertag, Brodie \& LeMaire (1984) blocked the LH-induced early rise in oestradiol in the perfusate and follicular fluid by a specific aromatase inhibitor and found no influence on ovulation rate or timing. Furthermore, manipulation of the low oestradiol levels just before ovulation to pharmacologically high levels did not 

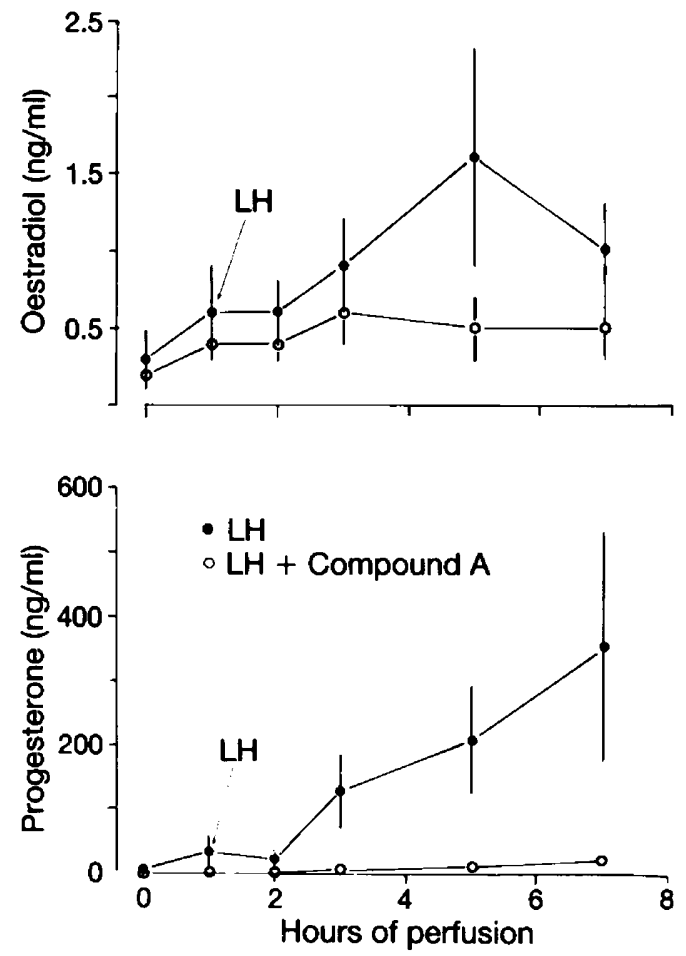

Text-fig. 2. Progesterone and oestradiol-17ß concentrations (mean \pm s.e.m.) in the medium from 5 pairs of rabbit ovaries perfused with and without Compound $A\left(1.6 \times 10^{-5}-1 \times\right.$ $\left.10^{-4} \mathrm{M}\right)$. LH $(0.75 \mu \mathrm{g} / \mathrm{ml})$ was added to both ovaries at $1 \mathrm{~h}$ of perfusion. Perfusions were stopped at $7 \mathrm{~h}$ before ovulation and follicular fluid contents of progesterone and oestradiol were measured.

Table 2. Ovulatory response of rabbit ovaries perfused in vitro after $\mathrm{LH}(0.75 \mu \mathrm{g} / \mathrm{ml})$ with or without the addition of progesterone $(10 \mu \mathrm{g} / \mathrm{ml})$

\begin{tabular}{lccc}
\hline & LH & LH + progesterone & Significance \\
\hline Total no. of ovaries & 13 & 13 & - \\
No. of ovaries with ovulating follicles & 11 & 4 & $P \leqslant 0.01\left(\chi^{2}\right.$ test) \\
Total no. of ovulations & 26 & 15 & - \\
No. of ovulations/ovulating ovary & $2 \cdot 4 \pm 0.4$ & $3.8 \pm 1 \cdot 0$ & N.S. (paired $t$ test) \\
Time of first ovulation (h after LH) & $7 \cdot 2 \pm 0.9$ & $6 \cdot 0 \pm 0 \cdot 7$ & N.S. (paired $t$ test) \\
\hline
\end{tabular}

Values are mean \pm s.e.m.

influence the ovulatory process in the isolated perfused rabbit ovary (LeMaire et al., 1982). These reports suggest that oestradiol is not involved in the mechanism of follicular rupture in rabbits or rats.

In the present study we focused on the possible role of progesterone in ovulation, since this steroid has been shown to inhibit collagenase in cultures of tissue from the post-partum uterus (Jeffery, Coffey \& Eisen, 1971). Moreover, earlier studies have provided some indications that it is progesterone that may be critical to follicular rupture. For instance, Lipner \& Wendelken (1971) reported that treatment of rats with inhibitors known to act at early steps in the steroidogenic pathway blocked LH-induced ovulation. Moreover, Snyder et al. (1984) showed that a $3 \beta$ hydroxysteroid dehydrogenase blocker reduced plasma concentrations of progesterone and 
inhibited gonadotrophin stimulated ovulation in immature rats, while injections of progesterone reversed the ovulation block. Also, progesterone was shown to increase the distensibility of strips from follicle walls under incubation conditions (Rondell, 1974). In that study, the steroid inhibitor cyanoketone blocked the effects on follicle wall distensibility and progesterone reversed the blockade.

The foregoing reseach was taken some steps further in the present work by using a new inhibitor of steroid biosynthesis and by an application of pharmacologically elevated concentrations of progesterone in the preovulatory period. This was done in a well controlled in-vitro system retaining normal circulatory physiology while avoiding the variability of an in-vivo experiment. As can be seen from the perfusate and follicular fluid analyses, Compound A effectively blocked the LHinduced progesterone production to very low levels. Despite this inhibition, no effects were seen on ovulation rate, ovulation timing or oocyte maturation. The findings in the present investigation, that blockade of progesterone production during the preovulatory period did not affect ovulation or oocyte maturation, are in contrast to the findings of Lipner \& Wendelken (1971) that blockade of progesterone production in vivo inhibited ovulation in rats. However, in the study by Lipner $\&$ Wendelken (1971) exogenous progesterone was not shown to reverse the ovulation block. It is possible that the blocker used in these in-vitro rat experiments, aminoglutethimide, may have influenced ovulation by effects other than those on steroidogenesis. It has been established, for instance, that aminoglutethimide not only reduces the synthesis of progesterone and oestradiol but also significantly inhibits the synthesis of $\mathrm{E}$ and $\mathrm{F}$ prostaglandins. Prostaglandins have been implicated in the mechanisms of follicular rupture (for review, see Dennefors et al., 1983). The present finding that inhibition of progesterone synthesis has no effect on ovulation in the rabbit ovary is supported by studies in vivo of the rat ovary by Bullock \& Kappauf (1973) using cyanoketone and aminoglutethimide. However, contrary evidence has been presented for rats by Snyder $e$ t al. (1984).

The failure of Compound A to affect oocyte maturation is in agreement with the study of Billig, Hillensjö, Tsafriri, Magnusson \& Brodie (1983), in which different inhibitors drastically altered the pattern of steroid production in follicles from PMSG-treated rats, incubated with or without LH. None of the inhibitors changed the proportion of oocytes resuming meiosis in response to $\mathrm{LH}$ and there was no effect of the inhibitors on the oocytes in the absence of $\mathrm{LH}$.

Hamada, Wright \& Wallach (1979) found no effects on ovulation rate when they added progesterone and hCG to the isolated perfused rabbit ovary. In the present study, however, high exogenous progesterone values markedly reduced the number of ovaries with ovulating follicles after LH stimulation, although the ovulation rate of the ovaries that did ovulate tended to be higher. This possibility that progesterone can modify the ovulation rate has been suggested by Testart, Thebault \& Lefèvre (1983) who found an increase in follicular ruptures with addition of progesterone to cultured whole rabbit follicles. In view of the discrepancies in results obtained in different experimental systems, it appears to be necessary to apply a wider range of pharmacological doses of progesterone to clarify its effect on ovulation. The pharmacological dose used in the present experiments was chosen because we have previously shown that similar oestradiol doses are necessary to achieve a high enough intrafollicular concentration of the steroid (LeMaire et al., 1982).

In summary, inhibition of the initial, $\mathrm{LH}$-induced progesterone production in the rabbit ovary appears to have no effect on follicular rupture or oocyte maturation. However, progesterone in the period immediately preceding ovulation may have a modifying effect on the follicular rupture. More work needs to be done to clarify this point.

This work was supported by grants from the Swedish Medical Research Council (4982) and the Gothenburg Medical Society. We thank Professor Kurt Ahrèn for valuable discussions and suggestions, Gun Abrahamsson and Ingegärd Karlsson for skilled technical assistance, and Ann-Louise Dahl for careful preparation of the manuscript. 


\section{References}

Billig, H., Hillensjö, T., Tsafriri, A., Magnusson, C. \& Brodie, A. (1983) Nuclear maturation of follicleenclosed rat oocytes during inhibition of steroidogenesis. Gamete Res. 8, 79-86.

Bullock, D.W. \& Kappauf, B.H. (1973) Dissociation of gonadotropin induced ovulation and steroidogenesis in immature rats. Endocrinology 92, 1625-1628.

Cajander, S., Janson, P.O., LeMaire, W.J., Källfelt, B.J., Holmes, P.V., Ahrén, K. \& Bjersing, L. (1984) Studies on the morphology of the isolated perfused rabbit ovary. I. Effect of long term perfusion. Cell Tiss. Res. 235, 59-63.

Dennefors, B., Hamberger, L., Hillensjö, T., Holmes, P.V., Janson, P.O., Magnusson, C. \& Nilsson, L. (1983) Aspects concerning the role of prostaglandins in ovarian function. Acta obstet. gynaec. scand., Suppl. 113, 31-41.

Hamada, Y., Wright, K.H. \& Wallach, E.E. (1979) The effect of progesterone and human chorionic gonadotrophin on ovulation in the in vitro perfused ovary. Fert. Steril. 32, 335-339.

Hillensjö, T., Bauminger, S. \& Ahrén, K. (1976) Effects of $\mathbf{L H}$ on the pattern of steroid production by preovulatory follicles of PMS injected immature rats. Endocrinology 99, 996-1002.

Holmes, P.V., Janson, P.O., Sogn, J., Källfelt, B., LeMaire, W.J., Ahrén, K.B., Cajander, S. \& Bjersing, L. (1983) Effect of $\mathrm{PGF}_{2 \alpha}$ and indomethacin on ovulation and steroid production in the isolated perfused rabbit ovary. Acta endocr., Copenh. 104, 223-239.

Hunzicker-Dunn, M. (1979) Summary. In Ovarian Follicular Development and Function, pp. 347-351. Eds A. R. Midgley, Jr \& W. A. Sadler. Raven Press, New York.

Janson, P.O., LeMaire, W.J., Källfelt, B., Holmes, P.V., Cajander, S., Bjersing, L., Wiqvist, N. \& Ahrén, K. (1982) The study of ovulation in the isolated perfused rabbit ovary. I. Methodology and patterns of steroidogenesis. Biol. Reprod. 26, 456-465.
Jeffery, J.J., Cofiey, R.J. \& Eisen, A.Z. (1971) Studies on uterine collagenase in tissue culture. II. Effects of steroid hormones on enzyme production. Biochim. Biophys. Acta 252, $143-150$.

Koos, R.D., Feiertag, M.A., Brodie, A.M.H. \& LeMaire, W.J. (1984) Inhibition of estrogen synthesis does not inhibit luteinizing hormone-induced ovulation. Am. J. Obstet. Gynec. 148, 939-945.

LeMaire, W.J., Clark, M.E. \& Marsh, F.M. (1979) Biochemical mechanisms of ovulation. In Human Ovulation, pp. 159-175. Ed. E. S. E. Hafez, Elsevier/ North Holland Biochemical Press, Amsterdam.

LeMaire, W.J., Janson, P.O., Källfelt, B.J., Holmes, P.V., Cajander, S., Bjersing, L. \& Ahrén, K. (1982) The preovulatory decline in follicular estradiol is not required for ovulation in the rabbit. Acta endocr., Copenh. 101, 452-457.

Lipner, H. \& Wendelken, L. (1971) Inhibition of ovulation by inhibition of steroidogenesis in immature rats. Proc. Soc. exp. Biol. Med. 136, 1141-1145.

Patwardhan, V.V. \& Lanthier, A. (1979) Effects of inhibition of steroid biosynthesis on prostaglandin formation in rabbit follicles. Prostaglandins 18, $859-868$

Rondell, P. (1964) Follicular pressure and distensibility in ovulation. Am. J. Physiol. 207, 590-594.

Rondell, P. (1974) Role of steroid synthesis in the process of ovulation. Biol. Reprod. 10, 199-215.

Snyder, B.W., Beecham, G.D. \& Schane, H.P. (1984) Inhibition of ovulation in rats with Epostane, an inhibitor of $3 \beta$-hydroxysteroid dehydrogenase (41865). Proc. Soc. exp. Biol. Med. 176, 238-242.

Testart, J., Thebault, A. \& Lefèvre, B. (1983) In-vitro ovulation of rabbit ovarian follicles isolated after the endogenous gonadotrophin surge. J. Reprod. Fert. 62, 413-418.

YoungLai, E.V. (1972) Effect of mating on follicular fluid steroids in the rabbit. J. Reprod. Fert. 30, 157-159.

Received 10 December 1984 